\title{
A Contrast in Pathogenic Responses between C57BL/6J and BALB/CJ Mice Using a Model of Retinal Injury
}

\author{
Haoshen Shi, Abdul S. Ebrahim, and Elizabeth A. Berger
}

From the Department of Ophthalmology, Visual and Anatomical Sciences, Wayne State University School of Medicine, Detroit, Michigan

\author{
Accepted for publication \\ August 9, 2018. \\ Address correspondence to \\ Elizabeth A. Berger, Ph.D., \\ Department of Ophthalmology, \\ Visual and Anatomical Sci- \\ ences, Wayne State University \\ School of Medicine, $540 \mathrm{E}$. \\ Canfield Ave., Detroit, \\ MI 48201. E-mail: eberger@ \\ med.wayne.edu.
}

\begin{abstract}
Ischemia is associated with the pathogenesis of retinal disease, including diabetic retinopathy and glaucoma. As a result, the retinal ischemia/reperfusion injury model has been used to study neurovascular changes. Historically, murine models of retinal disease are established in C57BL/6J (B6) mice, which have been described as type 1-dominant responders. In bacterial keratitis models, B6 mice are susceptible, whereas BALB/cJ (BALB/c; type 2-dominant) mice exhibit a resistant phenotype. As such, we questioned whether the type 1/type 2 paradigm could be extrapolated to events associated with retinal pathogenesis. The current study compares the retinal response of $B 6$ with $B A L B / C$ mice to investigate strain-specific differences. Retinas were collected at 2 and 10 days after ischemia/reperfusion injury to examine differences in neurovascular degeneration, leukostasis, oxidative stress, glial activation, and select inflammatory mediators. Although both strains showed signs of retinal injury, significantly more damage was observed in B6 mice. Retinal thickness was reduced and vascular damage was more severe in B6 mice. Exacerbated response to injury in B6 versus BALB/C retinas was further supported by increased leukostasis, inflammatory mediators, reactive oxygen species, and lipid peroxidation. In addition, more terminal deoxynucleotidyl transferase-mediated dUTP nick-end labeling-positive cells and increased glial activation were detected in B6 mice. These data indicate that $\mathrm{B} 6$ and $\mathrm{BALB} / \mathrm{C}$ retinas differentially respond to injury, which has broader implications regarding the development and study of retinal diseases. (Am J Pathol 2018, 188: 2717-2728; https://doi.org/ 10.1016/j.ajpath.2018.08.010)
\end{abstract}

Ischemic conditions are generated when the vasculature is obstructed or constricted, resulting in an inadequate supply of oxygenated blood to a tissue site or organ. The retina is particularly prone to ischemia because of vascular occlusions, stroke, physical trauma, glaucoma, and even diabetes. As such, retinal ischemia/reperfusion (I/R) injury models have been used to recapitulate the neurovascular damage associated with diabetic retinopathy, in particular. ${ }^{1-3}$ Ischemia induces the production of free radicals, resulting in local inflammation and tissue damage. At the reperfusion stage, restoration of the blood supply leads to further accumulation of oxygen radicals, causing oxidative stress responses, such as lipid peroxidation, ${ }^{4,5}$ damage to residential retinal cells, and secretion of proinflammatory cytokines. Production of chemoattractants and adhesion molecules induces neutrophil and macrophage migration into the injured tissue. Accumulation of these activated inflammatory cells at the injured site elicits additional production of reactive oxygen species (ROS), cytokines, and chemokines, exacerbating local inflammation in the damaged tissue. The pathogenesis of diabetic retinopathy specifically is characterized, in large part, by elevated retinal ROS concentrations because of severe impairment of the ROS scavenging system. ROS accumulation occurs during retinal I/R injury, with resultant up-regulation of inflammation and vascular damage, reflecting pathophysiological changes that are similarly observed in diabetic retinopathy. ${ }^{2}$ Moreover, glaucoma is known to involve increased

Supported by NIH National Eye Institute (NEI) grant R01 EY023226 (E.A.B.) and core grant P30EY004068, and Research to Prevent Blindness. Disclosures: None declared. 
intraocular pressure, ischemia, and retinal ganglion cell death. ${ }^{6}$ Earlier studies have found that I/R promotes nitric oxide neurotoxicity, resulting in retinal neurodegeneration. ${ }^{7,8}$ This effect causes functional changes demonstrated by reduced amplitudes of a- and b-waves, as measured by electroretinogram. ${ }^{9}$ In addition, studies in rodent models have indicated retinal microvascular degeneration after retinal I/R injury. ${ }^{2}$ Retinal apoptosis, breakdown of the blood-retinal barrier, and exacerbated retinal microvascular leakage were also recorded after elevated intraocular pressure-induced ischemia and reperfusion. ${ }^{10}$ Thus, the retinal I/R model has been established as a reliable tool to mimic neurodegeneration, microvascular degeneration, and oxidative stress associated with retinal diseases, such as diabetic retinopathy and glaucoma.

Inflammation is regarded as a causal factor in the pathogenesis of many retinal diseases. In diabetic retinopathy, up-regulation of inflammatory markers, such as inducible nitric oxide synthase, intracellular adhesion molecule-1 (ICAM-1), vascular endothelial growth factor (VEGF), NF- $\mathrm{B}$, IL-1 $\beta$, IL-6, IL-8, cyclooxygenase-2 $(\mathrm{COX}-2)$, and tumor necrosis factor- $\alpha$ (TNF- $\alpha)$, not only emphasizes the importance of inflammation, but also suggests critical cross talk with other pathogenic pathways. ${ }^{11,12}$ Similarly, numerous inflammatory molecules have been indicated in the pathogenesis of glaucoma, including VEGF, inducible nitric oxide synthase, IL-6, IL-8, TNF- $\alpha$, IL-18, and COX-2. ${ }^{13}$ Up-regulation of many of these same inflammatory mediators has been reported after I/R injury in rodent models. ${ }^{2,14}$ Furthermore, increased leukocyte rolling and accumulation in the retinal microvasculature has also been observed after injury, ${ }^{15}$ corresponding to increased leukostasis that occurs during diabetic retinopathy. ${ }^{16}$

Years ago, Gorham et $\mathrm{al}^{17}$ described the genetic differences regarding the development of type 1 helper T-cell (Th1) versus Th2 responses in multiple mouse strains. C57BL/6J (B6) mice were found to favor Th1 development, whereas BALB/cJ (BALB/c) mice exhibited a Th2 dominant response. ${ }^{17}$ Lucey $^{18}$ evolved the Th2/Th1 reference to type $1 /$ type 2 , thus emphasizing cytokine function and denoting production by all cell types rather than only $\mathrm{CD} 4^{+}$ $\mathrm{T}$ cells as the sole source of these chemical mediators. This is further supported by a study showing that macrophages derived from B6 mice (compared with $\mathrm{BALB} / \mathrm{c}$ mice) produced higher levels of TNF- $\alpha$ and IL-12 after stimulation with macrophage-activating lipopeptide- 2 or lipopolysaccharide. ${ }^{19}$ The bias of differential immune responses between B6 and BALB/c mice has been further demonstrated in numerous disease models, such as chemical-induced asthma, ${ }^{20}$ cutaneous leishmaniasis, ${ }^{21}$ high-fat feeding, ${ }^{22}$ and atherogenesis. ${ }^{23}$ Regarding the eye, studies performed using an established murine model of Pseudomonas aeruginosa-induced corneal infection have extensively characterized the type 1/type 2 paradigm; type 1-dominant B6 mice undergo corneal perforation and are classified as susceptible, whereas type 2-dominant BALB/c mice exhibit a resistant phenotype that is characterized by a selflimiting infection (cornea heals). ${ }^{24-26}$ In the infectious keratitis model, type 1 dominance is typified by elevated and sustained proinflammatory mediators (IL-1 $\beta$, TNF- $\alpha$, and interferon- $\gamma$ ) that exacerbate the disease response. In contrast, the type 2 response is differentiated by the activation of proresolving pathways and anti-inflammatory mediators (IL-4 and IL-10) that limit inflammation with subsequent disease resolution. ${ }^{26}$ Despite studies examining chronic inflammation and disease pathogenesis, little is known regarding the influence of the type 1/type 2 paradigm in the retina. Therefore, the purpose of this study was to investigate the pathogenic response of the retina as it relates to the type 1 versus type 2 immune background using an intraocular $\mathrm{I} / \mathrm{R}$ injury model. We expect these findings will provide insight into the retinal response to ischemia, which is an event that is associated with ocular disease, and that more consideration will be placed on strain-specific models used to investigate disease pathogenesis, even beyond the eye.

\section{Materials and Methods}

\section{Intraocular Ischemia-Reperfusion}

$\mathrm{I} / \mathrm{R}$ was performed in 7-week-old male B6 and BALB/c mice purchased from the Jackson Laboratory (Bar Harbor, ME). Given the potential for sex as a biological factor in the retinal response to injury, the current study focused on male mice to reduce experimental variability. The anterior chamber of one eye was cannulated with a 30-gauge needle attached to a line infusing normal saline. While intraocular pressure was measured by a handheld tonometer (TONO Pen; Medtronic Solan, Jacksonville, FL), pressure was elevated to 80 to $90 \mathrm{~mm} \mathrm{Hg}$ with a pressure infuser (Infusurg; Ethox Corp., Buffalo, NY). The contralateral eye served as a control. After 90 minutes of ischemia, the needle was withdrawn, intraocular pressure was normalized, and reflow of the retinal circulation was documented visually. ${ }^{2}$ Retinas were harvested at 2 and 10 days after injury for analyses, as described later. All mouse experiments were approved by the Institutional Animal Care and Use Committee at Wayne State University (Detroit, MI; protocol 11-08-14).

\section{Neuronal Analysis}

At 2 days after I/R injury, whole eyes were removed, followed by a 30-minute fixation in $4 \%$ paraformaldehyde. Retinal sections ( $8 \mu \mathrm{m}$ thick) were stained using hematoxylin and eosin, then visualized by light microscopy for morphometry. Photomicrographs were assessed for retinal thickness, and cell numbers in the ganglion cell layer (GCL), inner nuclear layer (INL), and outer nuclear layer were quantitated. Retinal thickness and cell counts were 
assessed using Invitrogen EVOS FL Auto Cell Imaging System (Invitrogen, Carlsbad, CA).

\section{Vascular Analysis}

Whole eyes were enucleated at 10 days after I/R exposure and suspended in $10 \%$ buffered formalin for 5 days, and the retina was dissected in $40 \mathrm{U} / \mathrm{mL}$ elastase solution (Merck Millipore, Burlington, MA). The retinal vascular tree was dried onto a glass slide and stained with hematoxylin-periodic acidSchiff. Degenerate capillaries, identified as acellular capillary-sized tubes, were counted ${ }^{27}$ in midretina $(n=5$ fields). Degenerate capillaries were excluded if their average diameter was $<20 \%$ of surrounding healthy capillaries. ${ }^{28}$

\section{Leukostasis Analysis}

Leukostasis and infiltration of inflammatory cells into the retina were assessed by retinal whole mount immunofluorescence. At 2 days after $\mathrm{I} / \mathrm{R}$, whole eyes were removed and fixed in $4 \%$ paraformaldehyde in phosphate-buffered saline (PBS) for 30 minutes at room temperature before isolating retinas. Retinas were removed by orbital dissection, washed in tris-buffered saline (TBS), and blocked in TBS containing $0.3 \%$ Triton X-100 and 10\% normal goat serum for 1 hour at room temperature. This was followed by incubation with rabbit anti-mouse CD45 (1:100; Invitrogen) in TBS containing $0.3 \%$ Triton X-100 and 10\% normal goat serum for 2 days at $4{ }^{\circ} \mathrm{C}$. Retinas were then washed extensively in TBS containing $0.3 \%$ Triton X-100 for 24 hours, followed by incubation with Alexa Fluor-594-labeled goat anti-rabbit IgG (1:1000; Invitrogen) and Alexa Flour-488-labeled isolectin B4 from Griffonia simplicifolia (1:100; Invitrogen) in TBS containing $0.3 \%$ Triton X-100 for 24 hours at $4^{\circ} \mathrm{C}$. Retinas were then washed extensively in TBS for 24 hours, flat mounted onto glass slides, and coverslipped with FluorSave reagent (Merck Millipore). Images were acquired with a Leica SP8 laser-scanning confocal microscope (Leica Microsystems, Wetzlar, Germany).

\section{Enzyme-Linked Immunosorbent Assay}

Retinal lysates were prepared at 2 and 10 days after injury by sonication in lysis buffer containing protease and phosphatase inhibitors. IL-1 $\beta$ and TNF- $\alpha$ protein levels were measured by enzyme-linked immunosorbent assay (R\&D Systems, Minneapolis, MN). All samples were assayed in duplicate, per the manufacturer's instruction. Equal protein was loaded into all wells. The reported sensitivities of these assays are $4.8 \mathrm{pg} / \mathrm{mL}$ for $\mathrm{IL}-1 \beta$ and $7.21 \mathrm{pg} / \mathrm{mL}$ for TNF- $\alpha$.

\section{Western Blot Analysis}

Retinal lysates were prepared at 2 days after injury for glial fibrillary acidic protein (GFAP) and hexanoyl-lysine adduct (HEL) analysis, and at both 2 and 10 days for inflammatory molecules. Equal amounts of total proteins were then separated onto $4 \%$ to $20 \%$ tris-glycine gels (Invitrogen) and transferred to nitrocellulose membranes. After blocking membranes in TBST $(10 \mathrm{mmol} / \mathrm{L}$ tris- $\mathrm{HCl}$ buffer, $\mathrm{pH} 8.0$, $150 \mathrm{mmol} / \mathrm{L} \mathrm{NaCl}$, and $0.1 \%$ Tween 20 ) and $5 \%(\mathrm{w} / \mathrm{v})$ bovine serum albumin at room temperature for 60 minutes, membranes were incubated overnight at $4^{\circ} \mathrm{C}$ with antigenspecific primary antibodies. The primary antibodies were used as follows: anti-HEL (1:500; AdipoGen Life Sciences, San Diego, CA), which detects HEL adduct formation attributable to lipid peroxidation; anti-GFAP (1:200; Thermo Fisher Scientific, Waltham, MA); anti-NF-кB p65 (phosphorylated Ser-536; 1:1000); anti-ICAM-1 (1:1000; Cell Signaling Technology, Danvers, MA); anti-VEGF (1:1000; Abcam, Cambridge, UK); anti-COX-2 (1:200); and anti- $\beta$-actin (1:1000; Santa Cruz Biotechnology, Dallas, TX). Blots were then incubated with species-specific horseradish peroxidase-conjugated secondary antibodies for 2 hours at room temperature. Proteins were visualized by incubation with a chemiluminescence substrate kit (Thermo Fisher Scientific). Western blot images were collected (Azure C500; Azure Biosystem, Dublin, CA), and target protein expression was quantified using Image Studio Lite software version 5.2 (LI-COR Biosciences, Lincoln, NE) after normalizing to $\beta$-actin. One representative blot is shown for each molecule.

\section{TUNEL Assay}

A terminal deoxynucleotidyl transferase-mediated dUTP nick-end labeling (TUNEL) assay (In Situ Cell Death Detection Kit, fluorescein; Roche, Mannheim, Germany) was performed at 2 days after injury to study retinal cell death on frozen sections ( $8 \mu \mathrm{m}$ thick), per manufacturer's instruction, followed by DAPI counterstaining $(300 \mathrm{nmol} / \mathrm{L}$; Thermo Fisher Scientific). TUNEL-positive cells were counted in retinal GCL, INL, and outer nuclear layer $(n=5$ areas per retinal section). Numbers were reported per millimeter of retinal surface. Images were acquired with Zeiss AxioImager with apotome light sectioning (Carl Zeiss AG, Oberkochen, Germany).

\section{Measurement of ROS Levels in the Retinal Lysates}

Retinal lysates $(10 \mu \mathrm{g})$ were incubated in reaction buffer [130 mmol/L KCl, $5 \mathrm{mmol} / \mathrm{L} \mathrm{MgCl} 2,20 \mathrm{mmol} / \mathrm{L} \mathrm{NaH}_{2} \mathrm{PO}_{4}$, $20 \mathrm{mmol} / \mathrm{L}$ Tris-HCl, $\mathrm{pH} 7.4,30 \mathrm{mmol} / \mathrm{L}$ D-glucose, and 7.5 $\mu \mathrm{mol} / \mathrm{L} \quad 2^{\prime}, 7^{\prime}$-dichlorofluorescin diacetate (DCFH-DA; Thermo Fisher Scientific)] for 1 hour at $37^{\circ} \mathrm{C}^{29}$ ROS oxidizes DCFH-DA, resulting in the formation of dichlorofluorescein, a detectable fluorescent product. ${ }^{30}$ Negative controls were incubated in reaction buffer without DCFHDA. Fluorescence levels were measured by SpectraMax M3 Multi-Mode reader (Molecular Devices, Sunnyvale, CA). The excitation and emission wavelengths used were 485 and $527 \mathrm{~nm}$, respectively. ${ }^{29}$ The final fluorescent values 
were acquired by calculating dichlorofluorescein fluorescent values minus negative control values.

\section{Immunofluorescence}

Eyes were isolated at 2 days after I/R injury for immunofluorescence staining. Whole eyes were fixed in $4 \%$ paraformaldehyde for 30 minutes in PBS. The whole eye was then transferred to $0.1 \mathrm{~mol} / \mathrm{L}$ PBS containing $30 \%$ sucrose for cryoprotection. Sections ( $8 \mu \mathrm{m}$ thick) were cut using a cryostat machine and stored at $-80^{\circ} \mathrm{C}$ until use. The sections were then blocked in PBS containing $0.3 \%$ Triton $\mathrm{X}-100$ and $10 \%$ normal goat serum for 1 hour, followed by incubation with mouse anti-mouse GFAP (1:100; Thermo Fisher Scientific) overnight in PBS containing 0.3\% Triton $\mathrm{X}-100$ at $4^{\circ} \mathrm{C}$. Sections were then washed three times in PBS and incubated with Alexa Fluor-488-labeled goat anti-mouse IgG (1:100; Thermo Fisher Scientific) in PBS containing $0.3 \%$ Triton $\mathrm{X}-100$ for 2 hours at room temperature. After rinsing with PBS $(\times 2)$, slides were incubated in DAPI counterstaining $(300 \mathrm{nmol} / \mathrm{L}$; Thermo Fisher Scientific), followed by additional PBS washes $(\times 3)$, and coverslipped with FluorSave reagent (Merck Millipore). Images were acquired with Leica SP8 laser-scanning confocal microscope.

\section{Statistical Analysis}

Sample sizes were determined statistically before experimentation. All assays were performed from at least five independent experiments, and the data are presented as means \pm SD. Data were acquired in a blinded manner (H.S. and A.S.E.) and analyzed by the analysis of variance test with Tukey's post-hoc test and multiple comparison. $P<0.05$ was considered statistically significant.

\section{Results}

\section{B6 Mice Exhibit Increased Neurodegeneration in Response to I/R Compared with BALB/c Mice}

To begin investigating whether retinas of type 1-dominant B6 versus type 2-dominant BALB/c mice exhibit straindependent differences in response to I/R-induced injury,

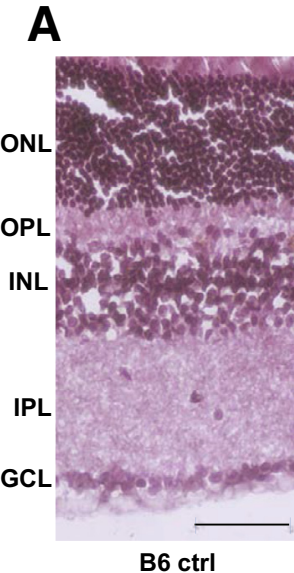

B6 ctrl

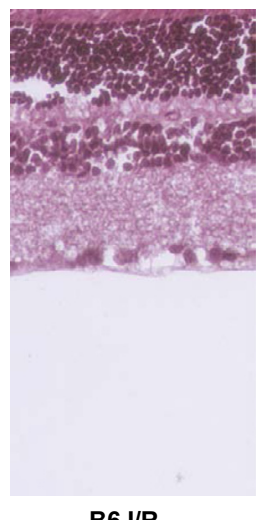

B6 I/R

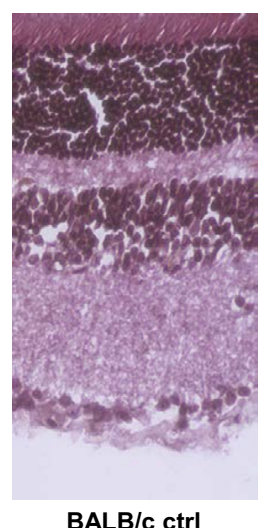

BALB/c ctrl

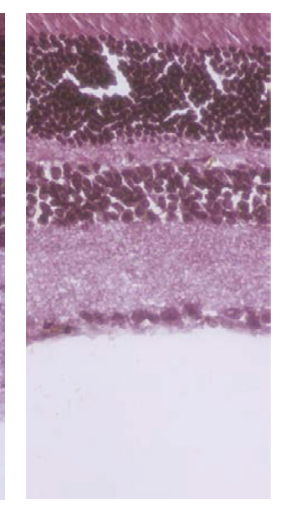

BALB/C I/R
B



C

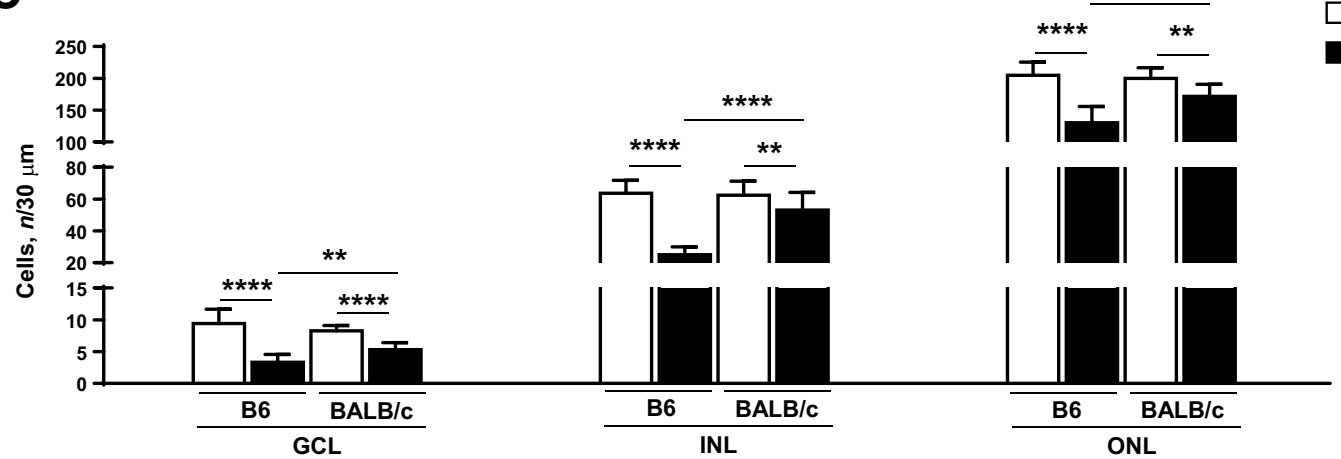

Figure 1 B6 retina exhibits significantly increased neurodegeneration compared with $B A L B / C$ retina after ischemia/reperfusion (I/R) injury. A: Retinal morphology with hematoxylin/eosin staining isolated from B6 and BALB/C eyes under control (ctrl)/normal conditions and at 2 days after I/R injury. B: Quantitative changes in retinal thickness. C: Quantitative changes in retinal ganglion cell layer (GCL), inner nuclear layer (INL), and outer nuclear layer (ONL). Outer plexiform layer (OPL) and inner plexiform layer (IPL) are also indicated. Data are expressed as means \pm SD (B). $n=5$ independent experiments (B). ${ }^{* *} P<0.01,{ }^{* * * * P}<0.0001$. Scale bar $=50 \mu \mathrm{m}$ (A, all images). 
neuronal changes were assessed at 2 days by hematoxylin and eosin-stained sections (Figure 1A). Measurements of retinal thickness revealed no differences between $\mathrm{B} 6$ and BALB/c controls (Figure 1B). Both mouse strains showed significant decreases in retinal thickness after $I / R$ injury compared with respective noninjured control eyes. Furthermore, retinal thickness was significantly less in I/ R-injured B6 mice, indicating a $14 \%$ reduction over BALB/c after injury. In fact, significantly fewer retinal cells were detected in the GCL, INL, and outer nuclear layer (Figure 1C) in B6 versus BALB/c mice after I/R injury, which indicated $28 \%, 46 \%$, and $22 \%$ more cells had been lost, respectively.

\section{B6 Mice Exhibit More I/R-Induced Microvascular Damage in Comparison to BALB/c Mice}

Next, it was determined whether I/R-induced injury resulted in differences in retinal microvascular damage between B6 and BALB/c mice. Using hematoxylin-periodic acid-Schiff staining (Figure 2A), retinal vasculature was examined for
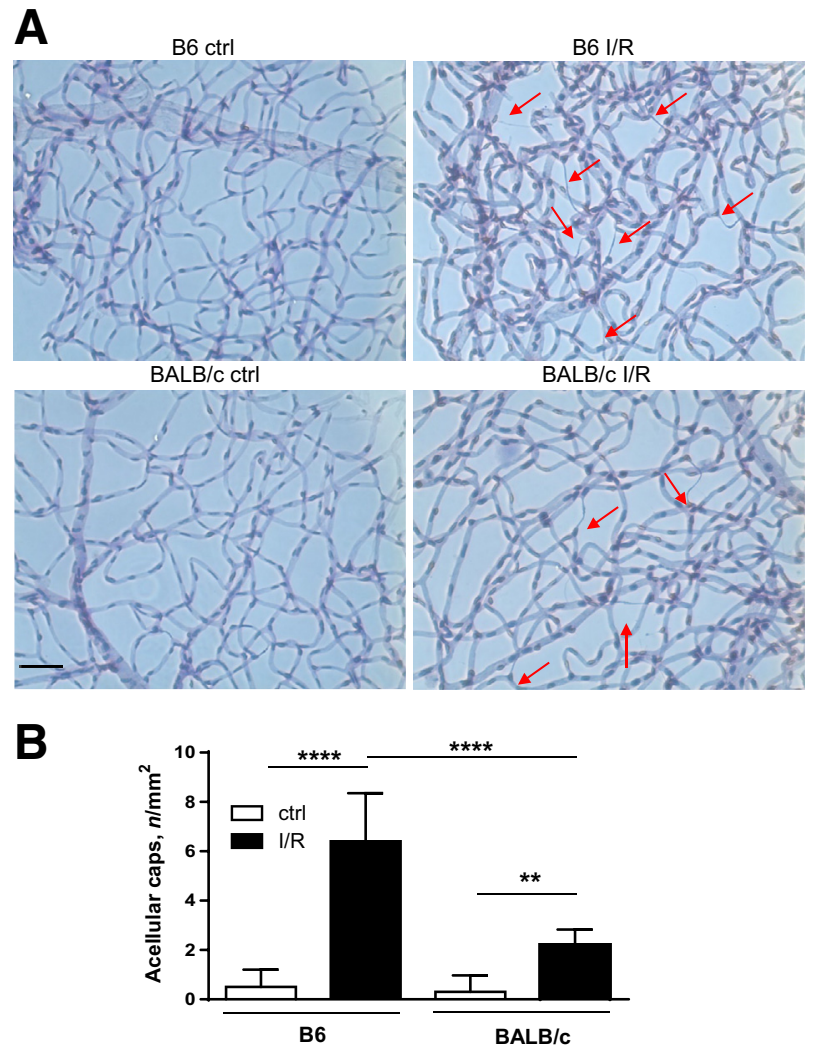

Figure 2 B6 retinas show significantly more microvascular degeneration compared with BALB/c retinas after ischemia/reperfusion (I/R) injury. $A$ : Isolated retinal microvasculature was stained with hematoxylin-periodic acid-Schiff to detect degenerated capillaries (red arrows) in B6 and BALB/C retinas of normal/control (ctrl) eyes and at 10 days after I/R injury. B: Quantification of acellular capillaries per $\mathrm{mm}^{2}$. Data are expressed as means $\pm \mathrm{SD}$ (B). $n=6$ independent experiments (B). ${ }^{* *} P<0.01$, $\star * * * P<0.0001$. Scale bar $=50 \mu \mathrm{m}$ (A, all images). degenerated acellular capillaries at 10 days after injury because vascular changes have been reported subsequent to neuronal damage. ${ }^{2}$ The numbers of degenerated acellular capillaries were increased in both B6 and BALB/c mice compared with controls, yet they were significantly increased in B6 versus $\mathrm{BALB} / \mathrm{c}$ mice after $\mathrm{I} / \mathrm{R}$ injury (Figure 2B). No differences were observed between the two strains in non-I/R, control retinas.

\section{I/R Induces Significantly More CD45 ${ }^{+}$Inflammatory Cell Infiltration in B6 Mice}

Leukocyte migration and adhesion to the retinal vasculature contributes to retinal disease pathogenesis. Differences in leukostasis were examined between the two mouse strains, which may contribute to the exacerbated response observed in $\mathrm{B} 6$ versus $\mathrm{BALB} / \mathrm{c}$ mice after $\mathrm{I} / \mathrm{R}$ injury at 2 days. Under normal conditions, no positive CD45 staining was detected in the retinal vasculature of either B6 or BALB/c mice; little positive staining was observed outside of the isolectin B4-positive vasculature in both mouse strains (Figure 3). After I/R, greater $\mathrm{CD} 45^{+}$staining was detected in both B6 and $\mathrm{BALB} / \mathrm{c}$ retinas compared with respective controls. However, compared with $\mathrm{BALB} / \mathrm{c}$ mice, I/R resulted in more $\mathrm{CD}_{4} 5^{+}$leukocytes in B6 mice. Numerous $\mathrm{CD} 45^{+}$ cells were observed extensively outside of the vasculature of B6 injured retinas; fewer $\mathrm{CD}^{+} 5^{+}$cells were detected in $\mathrm{BALB} / \mathrm{c}$ injured retinas, with most of these cells located within the vessels. A significant increase in $\mathrm{CD} 45^{+}$cells was quantitated in B6 versus BALB/c retinas after injury, as well (Figure 3).

\section{Retinas of Type 1-Dominant B6 Mice Exhibit Increased Inflammatory Activity in Response to I/R Compared with Type 2-Dominant BALB/c Mice}

Given the role of inflammation in driving disease pathogenesis, it was next investigated whether retinal I/R injury induced a differential response in type 2 versus type 1 mice. Protein levels of select inflammatory mediators were analyzed at 2 and 10 days after injury. In the $I / R$ retina, significant up-regulation of IL- $1 \beta$, TNF- $\alpha$, phosphorylated NF- $\kappa \mathrm{B}$, VEGF, ICAM-1, and COX-2 was observed in B6 mice at 2 days compared with controls (Figure 4). These same molecules, except VEGF, remained significantly elevated at 10 days as well. Regarding $\mathrm{BALB} / \mathrm{c}$ mice, significant increases were limited to TNF- $\alpha$ (2 days only), NF- $\kappa \mathrm{B}$ phosphorylation, and ICAM-1 after injury. Retinal levels of IL-1 $\beta$, VEGF, and $\mathrm{COX}-2$ in $\mathrm{BALB} / \mathrm{c}$ injured mice remained similar to controls.

Comparing the response between mouse strains, IL-1 $\beta$ and VEGF levels were higher at both time points in B6 over BALB/c mice, whereas TNF- $\alpha$ and COX-2 were similar between both strains at 2 days, then significantly elevated at 10 days after injury in B6 mice. Surprisingly, 
A



B6 I/R
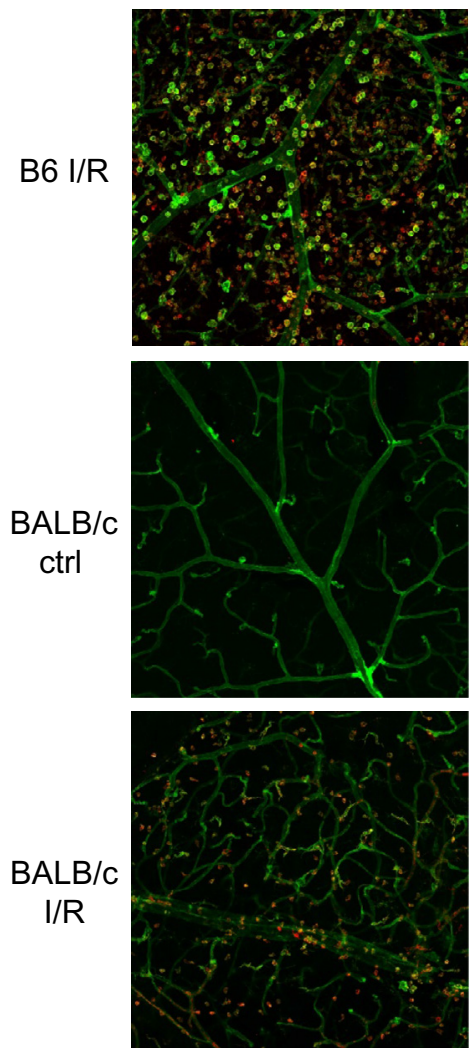

IB4
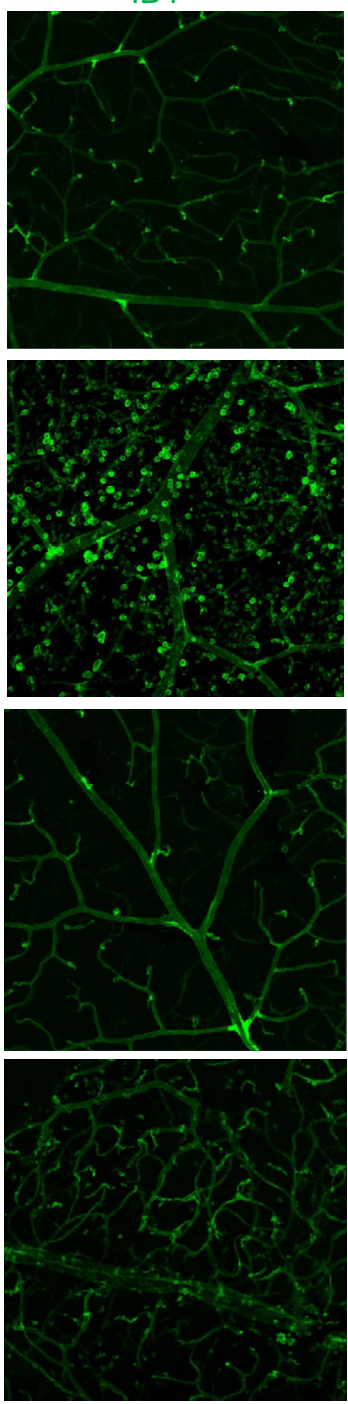

CD45
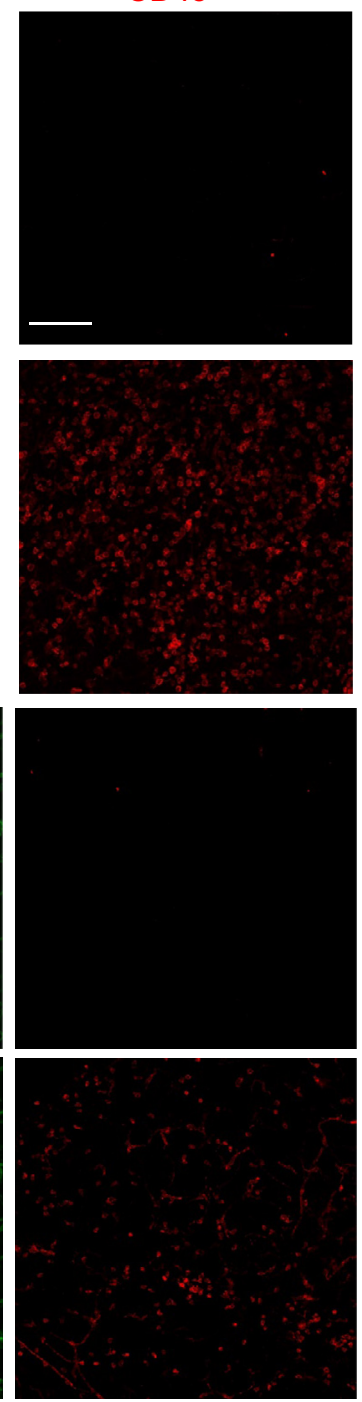

B

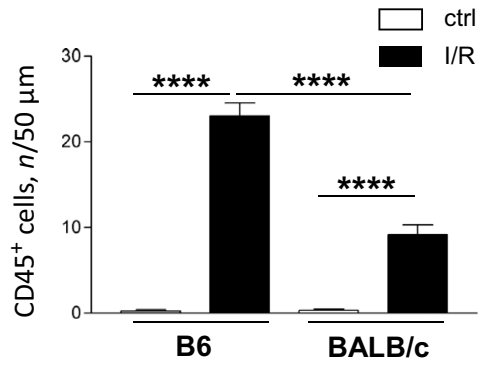

Figure 3 Increased leukostasis in B6 ischemia/reperfusion (I/R)-injured retinas compared with $B A L B / C$ retinas. A: Retinal flat mounts were isolated from $B 6$ and $B A L B / C$ normal controls (ctrls) and at 2 days after injury, then stained with antibodies to CD45 (red) and isolectin B4 (IB4; green). Representative images are provided, showing $\mathrm{IB}^{+}{ }^{+}$retinal microvasculature and $\mathrm{CD}_{4} 5^{+}$leukocytes. B: Quantification of $\mathrm{CD}_{4} 5^{+}$cells is presented in the bar graph. $n=5$ independent experiments (B). $\star * * * P<0.0001$. Scale bar $=50 \mu \mathrm{m}(\mathbf{A}$, all images). basal levels of COX-2 were significantly higher in BALB/ c compared with $\mathrm{B} 6$ retinas. Comparatively, there were no significant differences in phosphorylated NF- $\kappa$ B levels between B6 and BALB/c mice under normal conditions or after injury. Collectively, these results indicate a distinct strain-specific difference in response to retinal I/R injury, whereby B6 mice demonstrate a more robust and sustained proinflammatory profile compared with BALB/c mice.

\section{I/R-Induced Increase in Retinal Cell Death Is Observed in B6 Compared with BALB/c Mice}

Retinal cell death contributes to the cell loss in response to retinal I/R injury. Results in Figure $5 \mathrm{~A}$ revealed more TUNEL $^{+}$staining in B6 and BALB/c retinas after injury compared with controls. This was reflected by significantly more $\mathrm{TUNEL}^{+}$cells in all three retinal neuron layers (GCL,
INL, and outer nuclear layer) after I/R injury in both B6 and BALB/c mice (Figure 5B). Consistent with neuronal analysis, significantly more $\mathrm{TUNEL}^{+}$cells were quantitated in B6 mice after I/R injury compared with BALB/c mice, further indicating a differential response to injury between these two strains.

ROS Levels Are Significantly Up-Regulated in B6 versus $B A L B / c$ Mice with I/R Injury

Because ROS is the predominant pathogenic mechanism driving inflammation-induced tissue damage subsequent to I/R injury, ${ }^{4,5}$ potential differences in ROS levels between mouse strains were next examined. DCFH-DA detects most ROS, including one-electron-oxidizing species, heme proteins, oxidation-reduction-active metals, and hydrogen peroxide. ${ }^{30}$ Significantly increased levels of ROS, as determined by DCFH-DA, were limited 
A

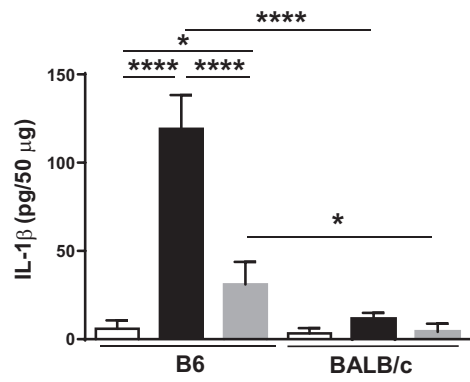

D

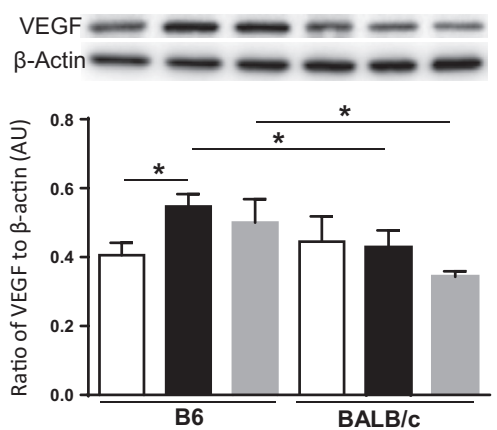

B

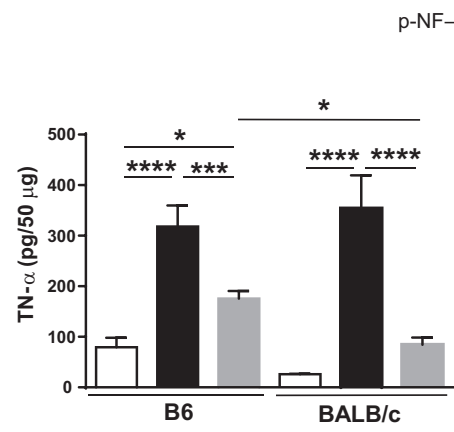

E

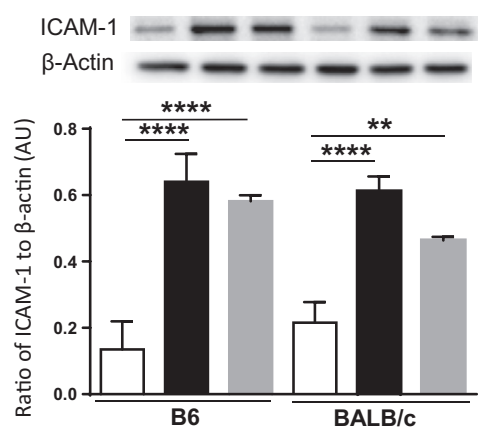

C

p65 (Ser-536)
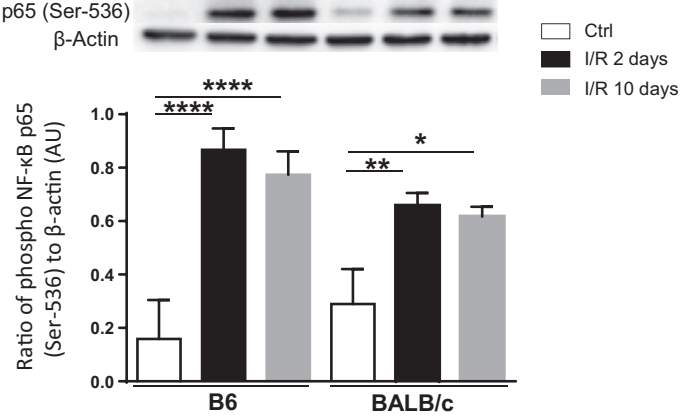

$\mathbf{F}$

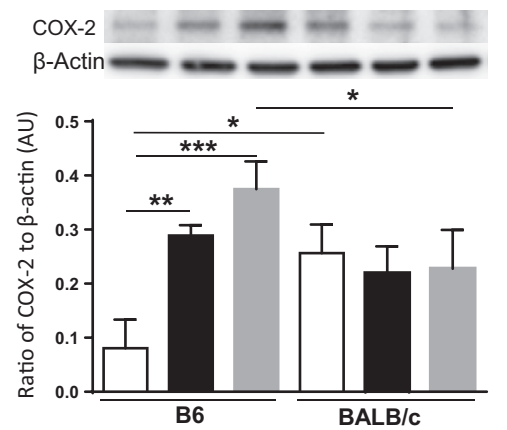

Figure 4 Increased inflammation detected in B6 versus BALB/C retinas after ischemia/reperfusion (I/R) injury. Retinal lysates were processed under normal conditions and at 2 and 10 days after injury for protein levels of select proinflammatory mediators: IL-1 $\beta$ (A), tumor necrosis factor (TNF)- $\alpha$ (B), phosphorylated NF-KB p65 at Ser-536 (C), vascular endothelial growth factor (VEGF; D), intracellular adhesion molecule-1 (ICAM-1; E), and cyclooxygenase-2 $($ COX-2; F). One representative gel image is provided for each Western blot. Data are expressed as means $\pm \mathrm{SD}(\mathbf{A}-\mathbf{F}) . n=5$ independent experiments $(\mathbf{A}-\mathbf{F})$. ${ }^{\star} P<0.05,{ }^{* *} P<0.01,{ }^{* * *} P<0.001$, and ${ }^{* * * *} P<0.0001$. AU, arbitrary unit; Ctrl, control.

to $\mathrm{B} 6$ mice after $\mathrm{I} / \mathrm{R}$ injury, whereas $\mathrm{BALB} / \mathrm{c}-\mathrm{I} / \mathrm{R}$ mice remained comparable to both $\mathrm{B} 6$ and $\mathrm{BALB} / \mathrm{c}$ controls (Figure 6A).

\section{Significantly Increased Lipid Peroxidation Is Observed in B6 Mice after I/R Compared with BALB/c Mice}

ROS-induced lipid peroxidation results in the formation of HEL. These adducts are formed by oxidative modification of $\omega-6$ fatty acids linoleic acid and arachidonic acid. After I/ $\mathrm{R}$ injury at 2 days, B6 mice displayed strong lipid peroxidation with detectable HEL adduct formation at approximately $25 \mathrm{kDa}$ and approximately $47 \mathrm{kDa}$, whereas $\mathrm{BALB} / \mathrm{c}$ injured retinas only showed a band at approximately $25 \mathrm{kDa}$ (Figure 6B). Densitometric analysis of the predominate bands at approximately $47 \mathrm{kDa}$ (Figure 6C) and approximately $25 \mathrm{kDa}$ (Figure 6D) was consistent with what was observed regarding DCFH-DA results (Figure 6A). Although HEL formation at approximately 47 $\mathrm{kDa}$ was only observed in B6 injured retinas, there was a significant increase in the formation of HEL at approximately $25 \mathrm{kDa}$ in both $\mathrm{B} 6$ and $\mathrm{BALB} / \mathrm{c}$ injured retinas compared with respective controls, with significantly more detected in $\mathrm{B} 6$ versus $\mathrm{BALB} / \mathrm{c}$ retinas.

\section{B6 Mice Exhibit More Glial Cell Activation after I/R Injury}

GFAP has been historically regarded as a sensitive indicator of stress in the central nervous system by its up-regulation in astrocytes, whereas in the retina, it is primarily up-regulated by Müller cells. ${ }^{31}$ Increased $\mathrm{GFAP}^{+}$staining was observed in $\mathrm{B} 6 \mathrm{I} / \mathrm{R}$ retinas at 2 days after injury, which was not observed in BALB/c injured retinas (Figure 7A). Specifically, more GFAP staining of activated astrocytes in the GCL and Müller cells in the INL was detected in B6 compared with BALB/c retinas. Furthermore, protein levels detected by Western blot analysis corroborated these results; only B6 I/R retinas resulted in a significant GFAP increase, whereas levels in $\mathrm{BALB} / \mathrm{c} \mathrm{I} / \mathrm{R}$ retinas remained similar to both $\mathrm{B} 6$ and BALB/c controls (Figure 7B).

\section{Discussion}

Animal models are essential in helping to delineate the events of human disease pathogenesis. To this end, it was explored how innate immune background and subsequently strain selection influence disease progression and outcome in the retina. The bias of pathology between B6 

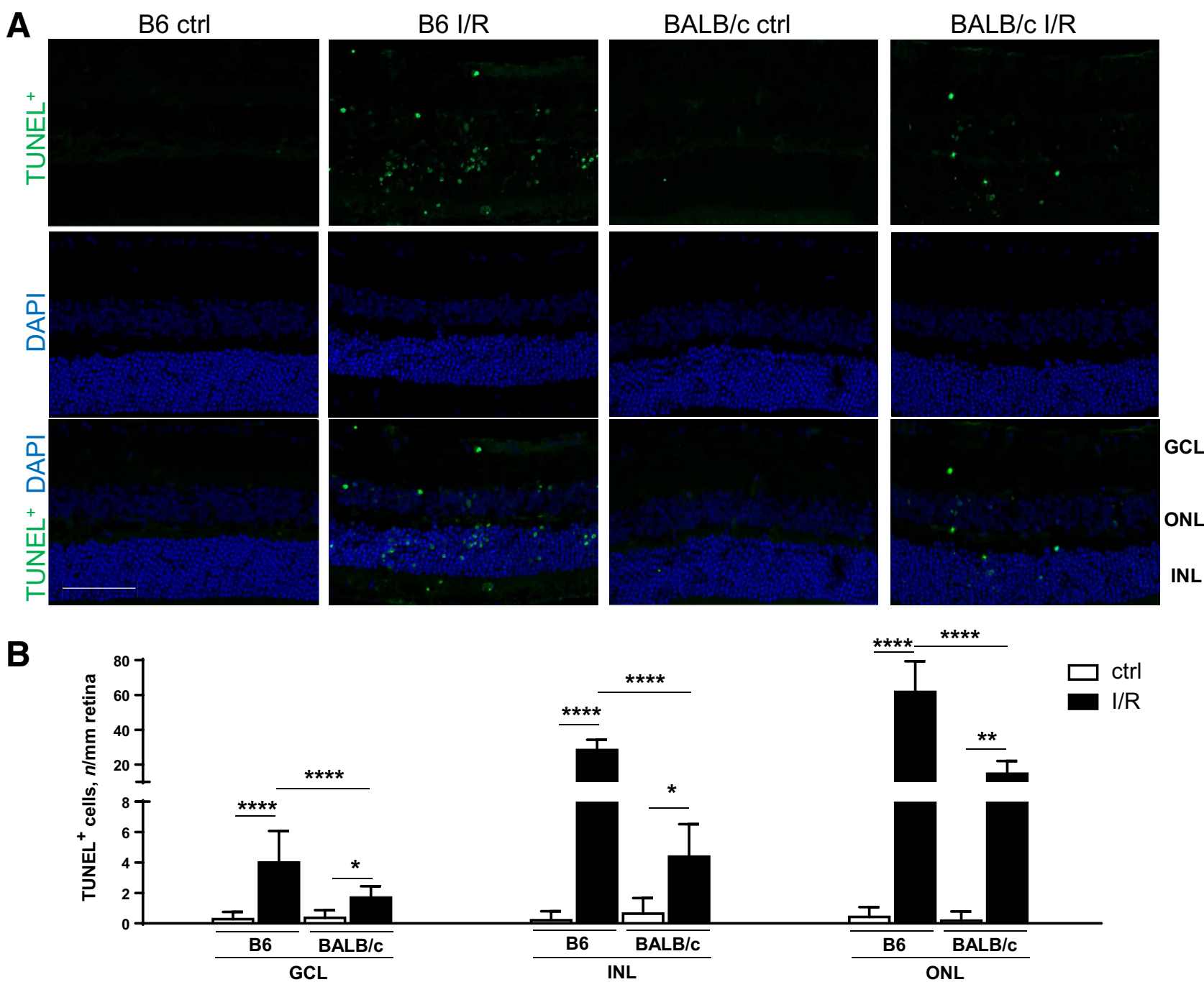

Figure 5 Significantly more terminal deoxynucleotidyl transferase-mediated dUTP nick-end labeling-positive (TUNEL ${ }^{+}$) cells are present in B6 ischemia/ reperfusion (I/R)-injured eyes compared with BALB/C eyes. A: Representative images of TUNEL staining in the retina of B6 and BALB/C mice under normal/ control (ctrl) conditions and at 2 days after I/R injury. Retinal sections were stained with TUNEL (green) and DAPI (blue). B: Quantification of TUNEL ${ }^{+}$cells in ganglion cell layer (GCL), inner nuclear layer (INL), and outer nuclear layer (ONL) is presented in the bar graph. Data are expressed as means \pm SD (B). $n=5$ independent experiments (B). ${ }^{*} P<0.05,{ }^{* *} P<0.01$, and ${ }^{* * *} P<0.0001$. Scale bar $=50 \mu \mathrm{m}$ (A, all images).

(type 1 responder) and $\mathrm{BALB} / \mathrm{c}$ (type 2 responder) mice has been demonstrated in the anterior eye from extensive $P$. aeruginosa-induced corneal infection studies. ${ }^{25,32-35}$ The current study extrapolates this paradigm to the posterior eye, in an effort to better understand the pathogenic events of retinal diseases, such as diabetic retinopathy and glaucoma. Regarding the former, based on a metaanalysis study, the overall prevalence of diabetic retinopathy in diabetic patients is now $34.6 \%$ for any stage, $6.96 \%$ for proliferative diabetic retinopathy, $6.81 \%$ for diabetic macular edema, and $10.2 \%$ for vision-threatening diabetic retinopathy. ${ }^{36}$ What is responsible for these differences observed in diabetic patients? Results herein provide insight as to a possible explanation-the genetically coded differences in host immune response. B6 mice have been traditionally used for streptozotocin
(STZ)-induced type 1 diabetic murine models in diabetic research. Male B6 mice are highly responsive to STZ, requiring a single $100-\mathrm{mg} / \mathrm{kg}$ dose. ${ }^{37}$ In contrast, male $\mathrm{BALB} / \mathrm{c}$ mice require a single dose of $150 \mathrm{mg} / \mathrm{kg}$ of STZ. ${ }^{38}$ Why is there a variation in STZ sensitivity between B6 and BALB/c mice? We hypothesize that strain background related to type 1 /type 2 profiles confers susceptibility to diabetic-induced changes. STZ-induced type 1 diabetes relies on pancreatic $\beta$-cell destruction, mediated by a T-cell-regulated autoimmune attack. ${ }^{39}$ In this regard, Müller et $\mathrm{al}^{40}$ reported differential regulation of type 1 versus type 2 inflammation profiles in pancreatic islets of B6 versus BALB/c mice with STZ injection: pancreatic islets of B6 mice respond to STZ with significant up-regulation of TNF- $\alpha$ and interferon- $\gamma$, whereas those of BALB/c mice expressed high levels of IL-4 and 

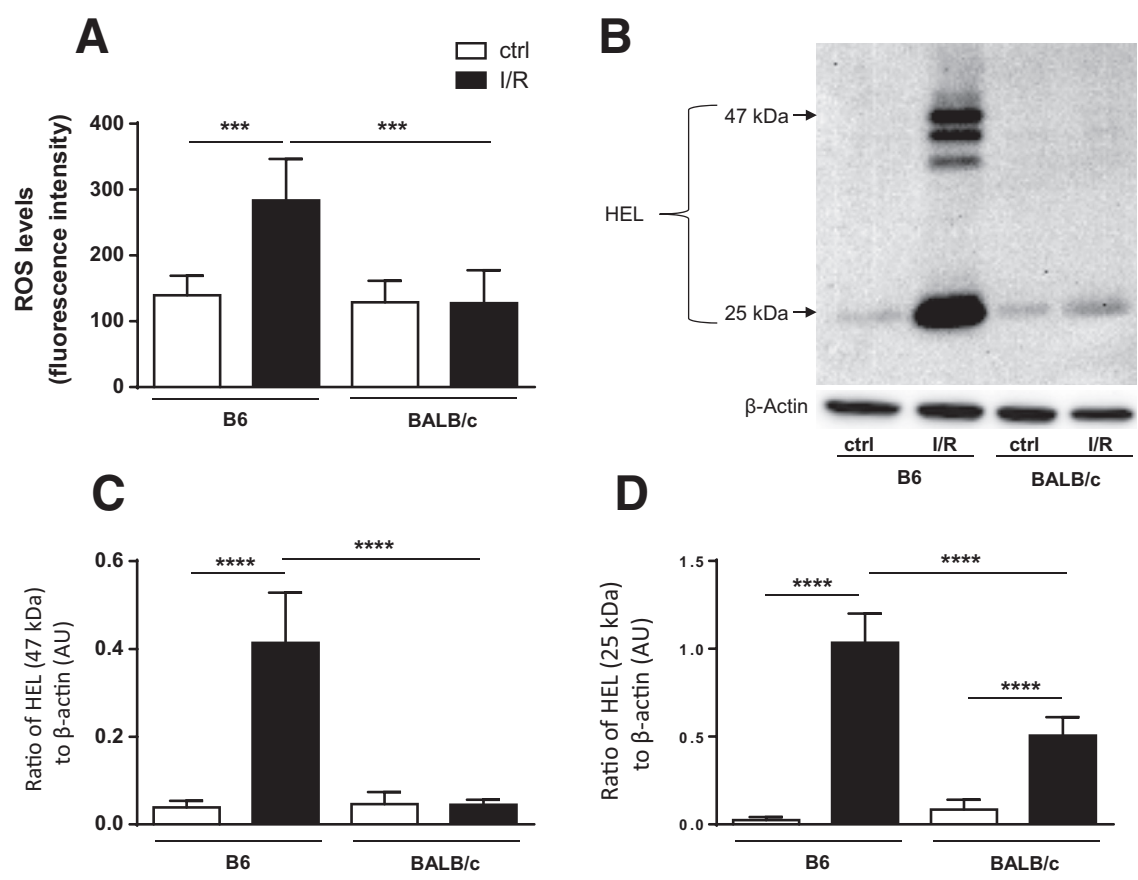

D

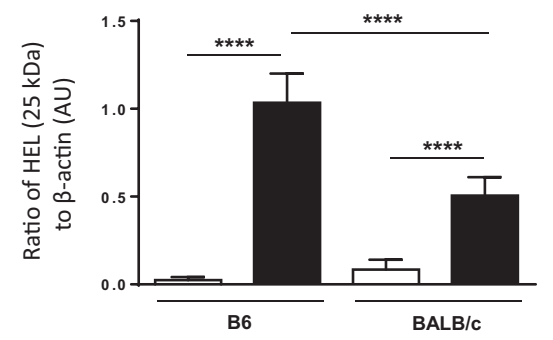

Figure 6 Retinas of B6 mice show more reactive oxygen species (ROS) and lipid peroxidation after ischemia/reperfusion (I/R) injury compared with $B A L B / c$ mice. Retinal lysates were collected from $B 6$ and BALB/c normal controls (ctrls) and at 2 days after I/R injury. A: ROS levels were determined by fluorescent values. Fluorescent values were acquired by subtraction of negative control values from $2^{\prime}, 7^{\prime}$-dichlorofluorescin diacetate values. B: Lipid peroxidation was determined by Western blot detection of hexanoyl-lysine adduct (HEL) formation in retinal lysates. C: Densitometric analysis of HEL formed at approximately 47 kDa. D: Densitometric analysis of HEL formed at approximately $25 \mathrm{kDa}$. Data are expressed as means \pm SD (A, C, and D). $n=5$ independent experiments (A, C, and D). ${ }^{* * *} P<0.001$, $* * * * P<0.0001$. AU, arbitrary unit.
IL-10, the latter of which are anti-inflammatory/protective cytokines. On the basis of these findings, it was predicted that B6 mice would display more retinal damage in response to $\mathrm{I} / \mathrm{R}$ injury and that this difference may be exploited to better understand the pathogenic events associated with retinal diseases.

Vascular pathology, including microvascular leakage and neovascularization, has been considered a major feature of the pathogenesis related to diabetic retinopathy. Straindependent variability has been shown in the oxygen-induced retinopathy model used to study retinal angiogenesis, ${ }^{41}$ where differences in oxygen vulnerability have been observed between B6 and BALB/c mice. ${ }^{42}$ In diabetic retinopathy, retinal microvascular damage is largely induced by inflammatory cells, particularly leukocyte-mediated retinal nonperfusion, cell junction disruption, and apoptosis of pericytes and retinal endothelial cells. ${ }^{12} \mathrm{We}$ observed not only more $\mathrm{CD} 45^{+}$inflammatory cell infiltrates in response to I/R-induced injury, but what appeared to be isolectin $\mathrm{B}^{+}{ }^{+}$staining of activated retinal microglial cells, as observed in B6 injured retinas. In addition, observed vascular pathology appeared to be attributed to the differential production of inflammatory mediators between B6 and $\mathrm{BALB} / \mathrm{c}$ injured retinas. Previously, intraocular I/R reports have demonstrated up-regulation of TNF- $\alpha, \mathrm{COX}-2$, NF- $\kappa$ B, ICAM-1, and VEGF. ${ }^{2,14}$ In this regard, B6 mice demonstrated an up-regulation of all inflammatory mediators examined, whereas the BALB/c response was not only less robust, but also temporally limited. Collectively, higher levels of inflammatory mediators and the stasis of more (activated) inflammatory cells in the B6 I/R injured retina appears to contribute to more severe retinal microvascular damage observed in comparison to the BALB/c retina.

The retina, formed embryonically from the diencephalon, undergoes neurodegenerative changes in response to injury, as well. Studies in glaucoma have shown that activated microglia promote a proinflammatory milieu that can exacerbate neuroinflammation and subsequent degeneration. ${ }^{43}$ Neurodegeneration has been observed early during the pathogenesis of diabetic retinopathy, predicting and contributing to later microvascular changes. ${ }^{44}$ However, the role of inflammation in contributing to this neurodegeneration remains less understood. Because cell death plays an important role in neurodegeneration, inflammation, and oxidative stress-induced cell damage, activated apoptosis may be one of the main contributors to neurodegenerative events. In addition, inflammation-induced pyroptosis is being considered the predominate model of retinal Müller cell death. ${ }^{45}$ Although neurodegeneration and cell death were observed in both mouse strains after retinal injury, B6 mice displayed significantly more pathology, which may also correlate with the robust inflammatory response observed in these animals. Closer examination of earlier time points (before 2 days) should uncover whether inflammation precedes retinal neurodegeneration or vice versa.

In ocular disease, dysregulated ROS activity plays an important role in retinal disease pathogenesis. ${ }^{46,47}$ The interrelationship between inflammation and ROS is emphasized in retinal disease; ROS-induced DNA damage can activate the NF- $\kappa \mathrm{B}$ pathway through poly (ADP-ribose) polymerase, $^{48,49}$ and NF- $\kappa \mathrm{B}$ further stimulates the 

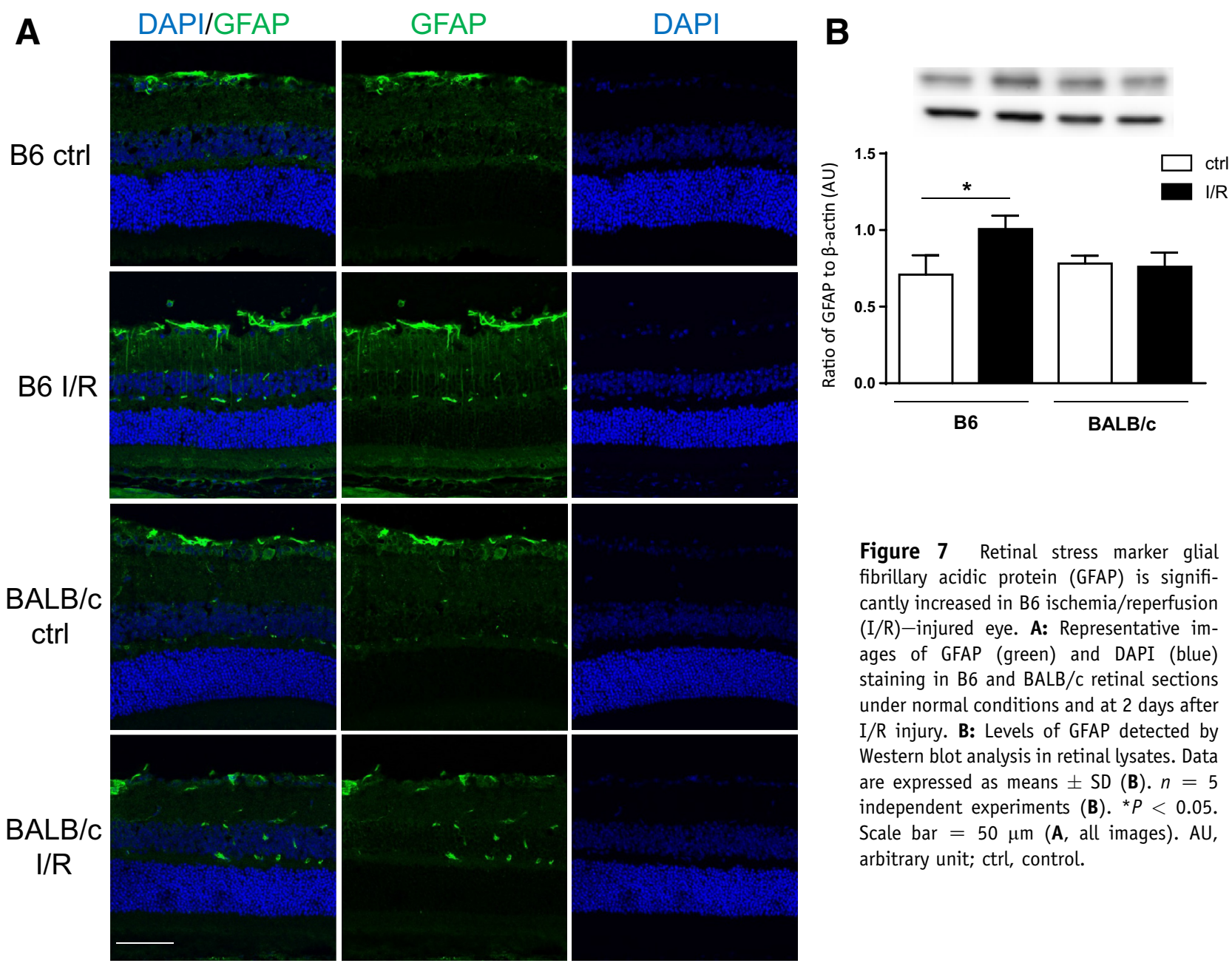

Figure 7 Retinal stress marker glial fibrillary acidic protein (GFAP) is significantly increased in $\mathrm{B} 6$ ischemia/reperfusion (I/R)-injured eye. A: Representative images of GFAP (green) and DAPI (blue) staining in $B 6$ and $B A L B / C$ retinal sections under normal conditions and at 2 days after I/R injury. B: Levels of GFAP detected by Western blot analysis in retinal lysates. Data are expressed as means \pm SD (B). $n=5$ independent experiments (B). ${ }^{*} P<0.05$. Scale bar $=50 \mu \mathrm{m}$ (A, all images). AU, arbitrary unit; ctrl, control.

expression of a wide spectrum of inflammatory molecules, which generates a positive feedback loop that exaggerates the ROS/inflammatory response. Therefore, we predicted that the more robust inflammatory response observed in B6 mice would elicit an exacerbated up-regulation of ROS and oxidative stress induced lipid peroxidation after retinal injury. Previous reports have suggested HEL formation as a novel biomarker for lipid peroxidation. ${ }^{50}$ Elucidating the formation of these adducts using B6 and BALB/c mice may prove to be an effective marker of retinal damage that precedes neurovascular changes.

\section{Conclusions}

Using an I/R injury model, we demonstrate exacerbated retinal inflammation, neurovascular degeneration, oxidative stress, and glial activation in B6 mice, which indicates that animals with a bias toward proinflammatory responses are more susceptible to inflammation/ROS-mediated retinal damage. Because both inflammation and oxidative stress are major pathogenic pathways in diabetic retinopathy and glaucoma, ${ }^{12,13,46}$ our finding using the I/R model warrants further investigation into both diabetic and glaucoma models to better understand how the paradigm of type 1/type 2 inflammatory bias affects retinal inflammation and disease. This will not only help us interpret why patients have different susceptibilities to the development of glaucoma and/or diabetic retinopathy complications, but also uncover potential intervention points of treatment to prevent both of these visually debilitating diseases.

\section{Acknowledgments}

We thank Dr. Jena Steinle and Li Liu for providing technical support and equipment for intraocular ischemia/ reperfusion surgery and retinal microvasculature study.

H.S. performed experiments, collected data, and wrote the manuscript; A.S.E. designed experiments and analyzed data; E.A.B. designed experiments, analyzed data, and wrote the manuscript; E.A.B. and A.S.E. edited the manuscript; all authors have read and approved this manuscript. 


\section{References}

1. Bresnick GH, Engerman R, Davis MD, de Venecia G, Myers FL: Patterns of ischemia in diabetic retinopathy. Trans Sect Ophthalmol Am Acad Ophthalmol Otolaryngol 1976, 81:OP694-OP709

2. Zheng L, Gong B, Hatala DA, Kern TS: Retinal ischemia and reperfusion causes capillary degeneration: similarities to diabetes. Invest Ophthalmol Vis Sci 2007, 48:361-367

3. Hartsock MJ, Cho H, Wu L, Chen WJ, Gong J, Duh EJ: A mouse model of retinal ischemia-reperfusion injury through elevation of intraocular pressure. J Vis Exp 2016, (113):54065

4. Flaherty JT: Myocardial injury mediated by oxygen free radicals. Am J Med 1991, 91:79S-85S

5. Kazui M, Andreoni KA, Williams GM, Perler BA, Bulkley GB, Beattie C, Donham RT, Sehnert SS, Burdick JF, Risby TH: Visceral lipid peroxidation occurs at reperfusion after supraceliac aortic crossclamping. J Vasc Surg 1994, 19:473-477

6. Evangelho K, Mogilevskaya M, Losada-Barragan M, VargasSanchez JK: Pathophysiology of primary open-angle glaucoma from a neuroinflammatory and neurotoxicity perspective: a review of the literature. Int Ophthalmol 2017, [Epub ahead of print] doi:10.1007/ s10792-017-0795-9

7. Hangai M, Yoshimura N, Hiroi K, Mandai M, Honda Y: Inducible nitric oxide synthase in retinal ischemia-reperfusion injury. Exp Eye Res 1996, 63:501-509

8. Neufeld AH, Kawai S, Das S, Vora S, Gachie E, Connor JR, Manning PT: Loss of retinal ganglion cells following retinal ischemia: the role of inducible nitric oxide synthase. Exp Eye Res 2002, 75:521-528

9. Jehle T, Wingert K, Dimitriu C, Meschede W, Lasseck J, Bach M, Lagreze WA: Quantification of ischemic damage in the rat retina: a comparative study using evoked potentials, electroretinography, and histology. Invest Ophthalmol Vis Sci 2008, 49:1056-1064

10. Abcouwer SF, Lin CM, Wolpert EB, Shanmugam S, Schaefer EW, Freeman WM, Barber AJ, Antonetti DA: Effects of ischemic preconditioning and bevacizumab on apoptosis and vascular permeability following retinal ischemia-reperfusion injury. Invest Ophthalmol Vis Sci 2010, 51:5920-5933

11. Kern TS: Contributions of inflammatory processes to the development of the early stages of diabetic retinopathy. Exp Diabetes Res 2007, 2007:95103

12. Tang J, Kern TS: Inflammation in diabetic retinopathy. Prog Retin Eye Res 2011, 30:343-358

13. Vohra R, Tsai JC, Kolko M: The role of inflammation in the pathogenesis of glaucoma. Surv Ophthalmol 2013, 58:311-320

14. Wang L, Li C, Guo H, Kern TS, Huang K, Zheng L: Curcumin inhibits neuronal and vascular degeneration in retina after ischemia and reperfusion injury. PLoS One 2011, 6:e23194

15. Miyahara S, Kiryu J, Tsujikawa A, Katsuta H, Nishijima K, Miyamoto K, Yamashiro K, Nonaka A, Honda Y: Argatroban attenuates leukocyte- and platelet-endothelial cell interactions after transient retinal ischemia. Stroke 2003, 34:2043-2049

16. Abiko T, Abiko A, Clermont AC, Shoelson B, Horio N, Takahashi J, Adamis AP, King GL, Bursell SE: Characterization of retinal leukostasis and hemodynamics in insulin resistance and diabetes: role of oxidants and protein kinase-C activation. Diabetes 2003, 52:829-837

17. Gorham JD, Guler ML, Steen RG, Mackey AJ, Daly MJ, Frederick K, Dietrich WF, Murphy KM: Genetic mapping of a murine locus controlling development of $\mathrm{T}$ helper 1/T helper 2 type responses. Proc Natl Acad Sci U S A 1996, 93:12467-12472

18. Lucey DR: Evolution of the type-1 (Th1)-type-2 (Th2) cytokine paradigm. Infect Dis Clin North Am 1999, 13:1-9. v

19. Watanabe H, Numata K, Ito T, Takagi K, Matsukawa A: Innate immune response in Th1- and Th2-dominant mouse strains. Shock 2004, 22:460-466
20. De Vooght V, Vanoirbeek JA, Luyts K, Haenen S, Nemery B, Hoet PH: Choice of mouse strain influences the outcome in a mouse model of chemical-induced asthma. PLoS One 2010, 5: e12581

21. Sypek JP, Chung CL, Mayor SE, Subramanyam JM, Goldman SJ, Sieburth DS, Wolf SF, Schaub RG: Resolution of cutaneous leishmaniasis: interleukin 12 initiates a protective $\mathrm{T}$ helper type 1 immune response. J Exp Med 1993, 177:1797-1802

22. Jovicic N, Jeftic I, Jovanovic I, Radosavljevic G, Arsenijevic N, Lukic ML, Pejnovic N: Differential immunometabolic phenotype in Th1 and Th2 dominant mouse strains in response to high-fat feeding. PLoS One 2015, 10:e0134089

23. Schulte S, Sukhova GK, Libby P: Genetically programmed biases in Th1 and Th2 immune responses modulate atherogenesis. Am J Pathol 2008, 172:1500-1508

24. Hazlett LD, McClellan S, Kwon B, Barrett R: Increased severity of Pseudomonas aeruginosa corneal infection in strains of mice designated as Th1 versus Th2 responsive. Invest Ophthalmol Vis Sci 2000, 41:805-810

25. Szliter EA, Lighvani S, Barrett RP, Hazlett LD: Vasoactive intestinal peptide balances pro- and anti-inflammatory cytokines in the Pseudomonas aeruginosa-infected cornea and protects against corneal perforation. J Immunol 2007, 178:1105-1114

26. Carion TW, Greenwood M, Ebrahim AS, Jerome A, Suvas S, Gronert K, Berger EA: Immunoregulatory role of 15-lipoxygenase in the pathogenesis of bacterial keratitis. FASEB J 2018, 32: 5026-5038

27. Jiang Y, Zhang Q, Liu L, Tang J, Kern TS, Steinle JJ: beta2Adrenergic receptor knockout mice exhibit A diabetic retinopathy phenotype. PLoS One 2013, 8:e70555

28. Kowluru RA, Tang J, Kern TS: Abnormalities of retinal metabolism in diabetes and experimental galactosemia, VII: effect of long-term administration of antioxidants on the development of retinopathy. Diabetes 2001, 50:1938-1942

29. Ishihara K, Amano K, Takaki E, Ebrahim AS, Shimohata A, Shibazaki N, Inoue I, Takaki M, Ueda Y, Sago H, Epstein CJ, Yamakawa K: Increased lipid peroxidation in Down's syndrome mouse models. J Neurochem 2009, 110:1965-1976

30. Kalyanaraman B, Darley-Usmar V, Davies KJ, Dennery PA, Forman HJ, Grisham MB, Mann GE, Moore K, Roberts LJ 2nd, Ischiropoulos $\mathrm{H}$ : Measuring reactive oxygen and nitrogen species with fluorescent probes: challenges and limitations. Free Radic Biol Med 2012, 52:1-6

31. Lewis GP, Fisher SK: Up-regulation of glial fibrillary acidic protein in response to retinal injury: its potential role in glial remodeling and a comparison to vimentin expression. Int Rev Cytol 2003, 230: 263-290

32. Carion T, Greenwood M, Gronert K, Berger EA: Lipid mediator pathways in the pathogenesis of bacterial keratitis. Invest Ophthalmol Vis Sci 2015, 56:5870

33. Huang X, Hazlett LD: Analysis of Pseudomonas aeruginosa corneal infection using an oligonucleotide microarray. Invest Ophthalmol Vis Sci 2003, 44:3409-3416

34. Berger EA, McClellan SA, Vistisen KS, Hazlett LD: HIF-1alpha is essential for effective PMN bacterial killing, antimicrobial peptide production and apoptosis in Pseudomonas aeruginosa keratitis. PLoS Pathog 2013, 9:e1003457

35. Hazlett LD: Corneal response to Pseudomonas aeruginosa infection. Prog Retin Eye Res 2004, 23:1-30

36. Yau JW, Rogers SL, Kawasaki R, Lamoureux EL, Kowalski JW, Bek T, et al; Meta-Analysis for Eye Disease (META-EYE) Study Group: Global prevalence and major risk factors of diabetic retinopathy. Diabetes Care 2012, 35:556-564

37. Lai AK, Lo AC: Animal models of diabetic retinopathy: summary and comparison. J Diabetes Res 2013, 2013:106594

38. Deeds MC, Anderson JM, Armstrong AS, Gastineau DA, Hiddinga HJ, Jahangir A, Eberhardt NL, Kudva YC: Single dose 
streptozotocin-induced diabetes: considerations for study design in islet transplantation models. Lab Anim 2011, 45:131-140

39. Atkinson MA: The pathogenesis and natural history of type 1 diabetes. Cold Spring Harb Perspect Med 2012, 2. pii:a007641

40. Müller A, Schott-Ohly P, Dohle C, Gleichmann H: Differential regulation of Th1-type and Th2-type cytokine profiles in pancreatic islets of $\mathrm{C} 57 \mathrm{BL} / 6$ and $\mathrm{BALB} / \mathrm{c}$ mice by multiple low doses of streptozotocin. Immunobiology 2002, 205:35-50

41. Kim CB, D'Amore PA, Connor KM: Revisiting the mouse model of oxygen-induced retinopathy. Eye Brain 2016, 8:67-79

42. Walsh N, Bravo-Nuevo A, Geller S, Stone J: Resistance of photoreceptors in the $\mathrm{C} 57 \mathrm{BL} / 6-\mathrm{c} 2 \mathrm{~J}, \mathrm{C} 57 \mathrm{BL} / 6 \mathrm{~J}$, and $\mathrm{BALB} / \mathrm{cJ}$ mouse strains to oxygen stress: evidence of an oxygen phenotype. Curr Eye Res 2004, 29:441-447

43. Ramirez AI, de Hoz R, Salobrar-Garcia E, Salazar JJ, Rojas B, Ajoy D, Lopez-Cuenca I, Rojas P, Trivino A, Ramirez JM: The role of microglia in retinal neurodegeneration: Alzheimer's disease, Parkinson, and glaucoma. Front Aging Neurosci 2017, 9:214
44. Villarroel M, Ciudin A, Hernandez C, Simo R: Neurodegeneration: an early event of diabetic retinopathy. World J Diabetes 2010, 1: $57-64$

45. Feenstra DJ, Yego EC, Mohr S: Modes of retinal cell death in diabetic retinopathy. J Clin Exp Ophthalmol 2013, 4:298

46. Izzotti A, Bagnis A, Sacca SC: The role of oxidative stress in glaucoma. Mutat Res 2006, 612:105-114

47. Kowluru RA, Chan PS: Oxidative stress and diabetic retinopathy. Exp Diabetes Res 2007, 2007:43603

48. Zheng L, Szabo C, Kern TS: Poly(ADP-ribose) polymerase is involved in the development of diabetic retinopathy via regulation of nuclear factor-kappaB. Diabetes 2004, 53:2960-2967

49. Tarr JM, Kaul K, Chopra M, Kohner EM, Chibber R: Pathophysiology of diabetic retinopathy. ISRN Ophthalmol 2013, 2013:343560

50. Sakai K, Kino S, Masuda A, Takeuchi M, Ochi T, Osredkar J, Rejc B, Gersak K, Ramarathnam N, Kato Y: Determination of HEL (hexanoyl-lysine adduct): a novel biomarker for omega-6 PUFA oxidation. Subcell Biochem 2014, 77:61-72 